\title{
Virtual, Paracosmic, Fictional
}

On being offered employment at a certain house 'near Millcote, —-shire', Jane Eyre 'brushed up my recollections of the map of England: yes, I saw it; both the shire and the town' ( $J E$ I05). Yet either the map or the England she consults must be different from our own, because while readers can only seek Thornfield abstractly, through 'historical inspirations' and filming locations, Jane unerringly places Millcote 'seventy miles nearer London' than her address at Lowood, and as 'a large manufacturing town on the banks of the A-' (I05). Charlotte Brontë's Jane Eyre is set, of course, in a fictional part of England, but it is worth pausing on the seeming obviousness of this expectation. How can a real country have a fictional part? Novel fiction engages its readers in protocols nearly invisible for the ease with which we assume them, as natural as reading, so much a matter of course that it requires a moment of obstinate naivete to register the paradoxical logic involved in 'setting' any realist novel within, but also necessarily out of, the spaces of real life. If Jane's relocation first seems less radical than the Indian mission she would later consider, her appeal to national reference abruptly defamiliarises an ostensibly familiar backdrop, revealing the apparent interstices of English geography that only inhabitants of the novel can see or enter. Much as Rochester continually teases Jane's plainness for disguising 'a fairy [...] come from Elfland' (337), the innocuousness of Millcote or Lowood as contemporary settings, measurable in miles from London and no more exotic than Leeds, belies 'the look of another world' (I 49).

The otherworldliness of novel fiction is a determining yet unacknowledged condition of the realist mode. It is in fact difficult to imagine the Victorian novel without the plausible yet invisible annexes its narratives interlock with the reference world of the reader: from the provincial neighbourhoods of Middlemarch and Barsetshire, to domestic spaces like Bleak House and Wuthering Heights, even to individual fictional rooms set into recognisable public buildings, the famously ordinary realist setting 
occupies a magical or quantum existence we take extraordinarily for granted. Bleak House's Mr Vhole keeps his office on the ground floor of the historical Symond's Inn, making him a close neighbour to Pendennis's Captain Costigan, who lives in the fictional Shepherd's Inn, nestled 'Some where behind the black gables and smutty chimney-stacks of Wych Street, Holywell Street, Chancery Lane [...] hidden from the outer world'. A national map riddled with such fairy glades, big and small - 'I saw it', says Jane, but what would such a map look like? - exemplifies the unusual, hybrid discourse which distinguishes the realist novel.

This book proposes the various ways mid-nineteenth-century novelists and readers find resources for living in this hybridity between fact and fiction, in imaginative practices I call virtual play. The four author studies that follow demonstrate these practices in action, exploring the implications and affordances of the novel's verisimilitude, in order to propose an alternative tradition of the novel as a medium for artificial realities. This chapter, however, lays the groundwork for these explorations by lingering on the idiosyncratic premise of fictional worlds and our naturalised capacity to entertain them, both products of the so-called rise of the novel which have become fundamental to modern fiction.

The idea that fictional discourse refers to a state of affairs outside the actual world is a philosophically intuitive and widely held model of narrative semantics: that what fictional sentences are doing when they talk as if Jane Eyre or Thornfield exist is positing an alternative reality where they do. ${ }^{2}$ Yet such narratological models, as Michael McKeon has argued, are 'largely drawn from the concrete practice of the novel genre' which has come to dominate understandings of fiction, even as its distinctive mode of extra-actual reference is, relative to the literary history of narratives in general, a recent invention of the eighteenth century. ${ }^{3}$ As historian of reading Jonathan Rose has stressed, not everyone even in the nineteenth century was caught up on the rules of a 'fairly sophisticated literary convention that must be learned', ${ }^{4}$ with credulous readers taking everything from the Revelations to Robinson Crusoe as literally and equivalently true to one unified history of actual events, an error only further complicated by the realist novel's seamless transitions between fictional and factual modes of reference (e.g., Sherlock Holmes lives on Baker Street). ${ }^{5}$ The capacity to virtualise narrative fiction, to engage the right protocols when encountering the realistic account of a non-actual world, enjoys the current status of a universal skill but has a specific literary history in the novel, as well as a set of practical literary functions which have become obscured by this taking for granted. 
Here as elsewhere in this book, I use 'play' as a heuristic to illustrate these possibilities of a virtualising capacity, and argue for their realisation in a practice of fiction intrinsic to the novel tradition. As the necessary form of response to what Gallagher calls the novel's 'language game' of reference without correspondence, play is an apt analogy for the navigation between cognitive frames required to maintain that London is connected by road to parts of the country that do not exist. ${ }^{6}$ More than an analogy, however, accounts of actual, specific play by nineteenth-century children also provide suggestive examples of a virtual practice in history, drawing on the same protocols of fiction as the novel form. How might play be novelistic? As Matthew Kaiser and J. Jeffrey Franklin have noted, play in its most philosophical form operated 'as the mystified kernel at the center of [Victorian] culture', uniting the disparate logics of competition, chance, fantasy, and leisure; much as it also provided for Kant the cornerstone of aesthetic judgement, and for Friedrich von Schiller the basis of human freedom. ${ }^{7}$ But the period also recognised 'play' more literally, in the sense of a specific activity with an imaginative or psychological component, which they alternatively described through the idioms of daydream, invention, make-believe, or castle-building. In the late eighteenth and early nineteenth centuries, a special kind of play in this latter sense began to be noticed among multiple groups of English children, prompting remarks from contemporary witnesses and later biographers on both its atypicality as a phenomenon and its conformity between cases. What developmental psychologists now neologise as paracosmic play or worldplay, a practice of extended make-believe premised on the creation and documentation of imaginary lands or worlds, continued throughout the twentieth century into the present day, but appear by the strength of the evidential record to have begun with a loose generation of late Romantics and early Victorians: with Hartley Coleridge, Anna Jameson, Thomas Malkin, Anthony Trollope, the De Quincey brothers, and the Brontë siblings.

The rise of novel fiction and of worldplay are concurrent historical narratives - and, as I propose, complementary ones. Both operate on a concept of fiction as an alternative plane of reference, existing nonmaterially yet concretely, independently yet in parallel to the actual; a set of assumptions which McKeon and Gallagher have shown to be significant and new for concepts of narrative and truthfulness in the eighteenth century. The distinctiveness and necessary sophistication of both have been eroded by familiarity, universalised by their persistence into our present ways of imagining fiction, and as such the two phenomena suggest similar questions - sharing potentially similar answers - about the 
development of our naturalised practices both on the historical and the biographical scale. Attempting to get at the particularities of what 'became the norm throughout Europe and America in the nineteenth century, and we still anticipate [...] when we pick up a novel today', Gallagher turns to the eighteenth century to 'hear what the novel has to say about fictionality in its infancy. ${ }^{8}$ Though it may be long forgotten, at some point we all 'learned' as a culture and as individuals to cry for the death of Little Nell without believing in her material life. As Rose points out, 'We are not born with this strategy of reading. ${ }^{9}$ In what follows, I argue that the history of worldplay is similarly revealing about the initial adoption of the fictional mode to which we now default, particularly in the cases of Trollope and Brontë, whose early play and juvenilia embody the learning of certain narrative assumptions which would underlie their later work as realist novelists. The complex protocols of fictional reality we necessarily perform, yet often elide when talking about the 'realist' settings of Barsetshire and Millcote are being visibly gestated in the imaginary worlds of paracosms, not having yet disguised their otherworldliness; fictionality captured in its infancy.

\section{Gombroon, Ejuxria, and Allestone}

Both my brother and myself, for the sake of varying our intellectual amusements, occupied ourselves at times in governing imaginary kingdoms. I do not mention this as any thing unusual; it is a common resource of mental activity and of aspiring energies amongst boys. ${ }^{\mathrm{IO}}$

Thomas De Quincey, writing about a childhood in the I790s, goes on to explain that 'My own kingdom was an island called Gombroon', which existed in 'one eternal element of feud' ( $A S$ 45) with Tigrosylvania, the kingdom of his older brother. The siblings took turns to determine the geographical position of their nations, a decision De Quincey deferred in the hopes of leaving 'a monstrous world of waters between us' (45) as a buffer against his brother's expansionism: on William's declaration that his capital lay on a latitude of sixty-five degrees north (just above the Bering Strait), 'That fact being once published and settled, instantly I smacked my little kingdom of Gombroon down into the tropics, Io deg., I think, south of the line [...] my brother never would degrade himself by fitting out a costly nautical expedition against poor little Gombroon; and how else could he get at me?' $(45-46)^{\text {II }}$ He had not counted, however, on William's riposte that Tigrosylanivan borders extended from its Arctic 
capital 'southwards through a matter of 80 or $90 \mathrm{deg}$. [...] vast horns and promontories ran down from all parts of his dominions towards any country whatsoever, in either hemisphere', (46) and moreover, that Gombroon's tropical forests concealed diamond mines its imperial neighbour intended to seize.

The De Quinceys' game is remarkable both for its precocity and its earnestness. For one, Gombroon and Tigrosylvania are governed by rules which support their capacity for true facts, information about the fictional world kept strictly consistent, specific, and accurate even while continually accumulated through play. Neither brother, in spite of their rivalry, ever attempt to reject each other's narrative claims or even to retract their own; once a fact is 'published and settled' $(A S 45)$, it can be extravagantly elaborated upon but never contradicted, 'like a move at chess or draughts, which it was childish to dispute' (46). As Sally Shuttleworth has also noted, 'there is curious interplay between the concepts of the real and imaginary: although this world is one of imagination, it obeys rigid rules of physicality and social intercourse'. ${ }^{\mathrm{I2}}$ A precise difference of seventy-five degrees in latitude is a distance which requires either 'a costly nautical expedition' (46) or an already sprawling empire to surmount; nations invade each other for concrete motives of resource-gathering, requiring a diegetic logic of the game in addition to a player's belligerence. Such details demand not only exactness but also an extensive coherence.

For another, although the siblings are clearly aware of a potential arbitrariness to facts they themselves invent (choosing, for instance, where to place landmasses), the imaginariness of objects and experiences do not diminish their value or seriousness. 'O reader, do not laugh!' De Quincey pleads in acknowledgement that, compared to his physical fights with local boys, Gombroon is 'a world purely aerial, where all the combats and the sufferings were absolute moonshine' $\left(A S_{47}\right)$. Yet, reversing the expected hierarchy, real life 'was as nothing in comparison of that dream kingdom which rose like a vapor from my own brain', because the 'Long contemplation of a shadow, earnest study for the welfare of that shadow [...] had gradually frozen that shadow into a rigor of reality far denser than the material realities of brass or granite' $(47-48)$. The more that the fictional world makes sense, the more it matters, and vice versa; the effort to maintain the specificity and self-consistency of the pretence renders it capable of real affective responses, just as emotional and imaginative participation in that pretence contributes to its feeling of inviolable reality.

Playing with imaginary worlds is an exemplarily and distinctively virtual practice, not only because it fore-'shadows' the language of digital virtual 
realities, but because the very concept of an imaginary world reflects the development of substantive new attitudes to literary fiction and truth in the eighteenth century. If the brothers' system of true invented facts appears as precocious but unexceptional to a modern culture where multiple print dictionaries document the Klingon language in English, Portuguese, German, Italian, and Czech, authors and readers of the early novel had arrived fitfully to the idea that a plausible report about concrete objects could be neither telling the truth nor lying about the actual, but instead relaying fictional information. Although the dishonesty of poetry has been consistently debated since Plato, the incipient genre of the novel was the first to formally frame fictional narratives as reports of real life, necessitating circumlocuitous defences like Daniel Defoe's I 7 I 9 preface to Robinson Crusoe, which (spuriously) claimed the tale to be 'a just History of Fact; neither is there any appearance of Fiction in it' yet also hedged his bets, 'because all such things are [disputed], that the Improvement of it, as well as the Diversion [...] will be the same'. ${ }^{13}$ Others, like Fielding, mounted Aristotelean arguments of the novel's general or abstract truthfulness - reporting the type of thing that can happen - even as the narrative seemed to describe specific instances in what Ian Watt seminally termed as 'formal realism'. ${ }^{4}$

Between Robinson Crusoe and, exactly a century later, The Bride of Lammermoor lies the naturalisation of an assumption which would render Defoe and Fielding's excuses unnecessary: the novel describes its own reality, overlapping with ours but maintaining its own rigorous system of reference and fact. Walter Scott's preface in I8 I9 identifies the 'real source' for Lammermoor's narrative but also the explicit imaginariness of his version of events. For instance, 'the death of the unfortunate bridegroom by a fall from horseback has been in the novel transferred' to a different character, and that although 'The imaginary castle of Wolf's Crag has been identified by some lover of locality with that of Fast Castle [...] The Author is not competent to judge of the resemblance betwixt the real and imaginary scenes, having never seen Fast Castle except from the sea'. ${ }^{\text {IS }}$ In the new protocols of fictionality between Scott and his readers, to attack his narrative as implausible by pointing out internal contradictions - for example, if two separate descriptions placed Wolfs Crag on opposite ends of Scotland - would be fair game, but to do so by disputing the historicity of its particulars (as Defoe once expected to be 'disputed') would not. The idea of a fictional world, to which play or narrative can refer instead of the actual world, is significant not just for its imagined space and objects but as a 
fundamental conceit for understanding how to read a novel in the nineteenth century.

De Quincey's account registers the acquisition of a novel literacy or cognitive skill by two particular children at the turn of the century, but larger implications about the cultural spread of these skills lie in his suggestion that such games represent a 'common resource of mental activity' $(A S 45)$ in this period. He specifically cites a fellow monarch in Hartley Coleridge (the son of his erstwhile idol Samuel Taylor Coleridge), who also 'had a kingdom which he governed for many years' (45). Derwent Coleridge's posthumous memoir of his younger brother recalls the imaginary land of Ejuxria, which Hartley invented as 'a region - a realm [...] an island-continent, with its own attendant isles,- a new Australia, or newest Sea-land'. ${ }^{16}$ Unlike William De Quincey, Derwent played confidant to his brother's fictions but did not participate, giving Hartley sole authorship over a less embattled realm than Gombroon:

[F] urnishing a theatre and scene of action, with dramatis personae [...] day after day, for the space of long years, he went on evolving the complicated drama of existence. There were many nations, continental and insular, each with its separate history, civil, ecclesiastical, and literary, its forms of religion and government, and specific national character. ( $H C$ xliii)

Contemporaneously yet independently, De Quincey and Coleridge converged on similar yet highly specific patterns of play. Common to both cases is a focus on consistency and detail, faithfully imagining a single world and its inhabitants over years and to great specificity. Both are drawn to the setting of the island, isolated by an indeterminate ocean but still nebulously located on the globe. More fundamentally, the two games also share a fictional mode. As an ambivalent yet enraptured spectator, Derwent made an incisive theoretical distinction that, although 'the Ejuxrian world presented a complete analogon to the world of fact [...] the correspondence was free and poetical, not in the nature of a fac-simile, nor, as in Gulliver's Travels, of an intentional disguise' (xliii-xliv). Like the imaginary Wolfs Crag, the 'analogon' of Ejuxria may resemble certain actualities, but it constitutes a reality which is specific and complete in itself. 'I believe it to have been a work of the imagination', Derwent concludes, 'woven with wonderful minuteness, and, as I believe, with uniform consistency' (xliv).

Both pairs of brothers were in turn unaware of another contemporary in Thomas Malkin (b. I795), the son of writer Benjamin Heath Malkin and 
an apparent child prodigy. After Thomas's tragic death from illness at the age of nine, the elder Malkin published in 1803 A Father's Memoirs of His Child to record the lost promise of his son's genius; in particular, the biography is dominated by narratives and sketches of Thomas's imagined world. This archive, which includes a fold-out facsimile of Thomas's map and an appendix of his writings (in addition to significant excerpts within the biographical text), presents a compelling model for the no longer extant 'publications' of Hartley and the De Quinceys:

This was the idea of a visionary country, called Allestone, which was so strongly impressed on his own mind, as to enable him to convey an intelligible and lively transcript of it in description. Of this delightful territory he considered himself as king. He had formed the project of writing its history, and had executed the plan in detached parts. Neither did his ingenuity stop here; for he drew a map of the country, giving names of his own invention to the principal mountains, rivers, cities, seaports, villages, and trading towns. ${ }^{17}$

Besides striking congruences in the practice of 'governing imaginary kingdoms' $(A S 45)$, the senior Malkin's account is also telling in its oscillation between Thomas's play as 'description' and as 'ingenuity', with the formal appearance of a referential or documentary activity (conveying a transcript, writing a history, drawing a map) belying the explicit ontology of fictionmaking (assuming kingship, inventing names). All three games operate on this elaborate double structure of fictional reference. Although 'no written record remains' of Hartley's Ejuxrian writings except 'the fragment of a story' ( $H C$ xlii), Derwent remembers that 'an elaborate map of the country was once in existence' (xlii-xliii). De Quincey recalls another instance of brotherly cruelty in how, on encountering Lord Monboddo's preDarwinian theories on human ancestry, William 'published an extract from some scoundrel's travels in Gombroon, according to which the Gombroonians had not yet emerged from this early condition of apedom. They, it seems, were still homines caudati [humans with tails]' ( $A S$ 52). Such maps, histories, and travel writings, borrowed forms which encourage their reception as true or false records of the actual, depend on the context of the game to be understood as fictional works referring to a fictional world; a strategy, as I have argued, that embodies a distinctively novelistic logic.

It of course bears noting that not all play of this kind and in this period conform so exactly in their features, but that the conceit of the fictional world is nonetheless a conspicuous marker for the availability of 'a common resource' ( $A S 45$ ). Anna Jameson (b. 1796), in her popular I 854 essay 
'A Revelation of Childhood', disproves De Quincey's assumption that imaginary kingdoms are the exclusive province of boys:

I can truly say that, from ten years old to fourteen or fifteen, I lived a double existence; one outward, linking me with the external sensible world, and other inward, creating a world to and for itself, conscious to itself only. I carried on whole years a series of action, scenes, and adventures; one springing out of another, and coloured and modified by increasing knowledge. ${ }^{18}$

Jameson's imagined 'world' (not named in the essay) bears generic differences from Gombroon, Ejuxria, and Allestone, designed to accommodate romances of her own adventures as 'a princess-heroine in the disguise of a knight [...] going about to redress the wrongs of the poor, fight giants, and kill dragons.'. ${ }^{19}$ Moreover, for Jameson the 'double existence' of 'inward' narration emphasises privacy over publication, noting that despite her 'very strict and very accomplished governess [...] nothing of this was known or even suspected by her, and I exulted in possessing something which her power could not reach'. ${ }^{20}$ Her language echoes the solipsistic practices of characters such as Lucy Snowe of Villette, published the year before, who similarly balances 'two lives - the life of thought, and that of reality', ${ }^{21}$ and of Jane Eyre tuning her 'inward ear to a tale that was never ended - a tale my imagination created, and narrated continuously' ( $J E$ I32). As we will see, such parallels to Brontë's protagonists ultimately trace back to another game of imagined worlds, but much else about Jameson's play also shares fundamental features with De Quincey, Coleridge, and Malkin: the 'founding [of] a society in some far-off solitude or desolate island', the assumption of an authority to mandate 'no tears, no tasks, and no laws, - except those which I made myself, and the continuation of the same or connected set of fictions over years. ${ }^{22}$

'It is an interesting question why', Shuttleworth suggests, 'at this period, children in such different households should have invested such energy in creating alternate lands [...] there are not, as far as I am aware, any earlier records of them attempting to create entire imaginary lands, complete with political, economic, and cultural systems.$^{23}$ I have argued so far that the spread of this practice parallels the popularisation of a literary form (the novel) and its narrative conventions (applicable beyond the novel), or understood together, represents the naturalisation of a type of virtual thinking about fiction. But as her question implies, Shuttleworth herself is less persuaded on the emergence of a child psychological phenomenon 'at this period', given only a correlation without causation between 
'such different households'. She proposes instead to explain an emergence of 'records', the dissemination of a mode of autobiography rather than of fictionality, wherein 'the publication of so many reflections on early childhood at the mid-[nineteenth] century [...] had a contagious effect, stimulating further revelations from writers turning to their own childhoods as a source of self-understanding. ${ }^{24}$ If the birthdates of these children appear to cluster in the 1780 os and 9os, the publications of their 'reflections' also closely follow each other: Derwent's memoir in I 85 I, De Quincey's Autobiographical Sketches in I853, and Jameson's essay in I $855 .{ }^{25}$ By this account, play with imaginary worlds may have existed long before the novel, but not considered worthy of comment until a new interest in representing childhood after Wordsworth and the bildungsroman.

The modern inheritors of this nineteenth-century interest - developmental psychology and the social sciences - have similarly understood this form of play to be a universal cognitive schema, a hypothesis strengthened by the continued manifestation of cases into the present day. Such studies, however, are less interested in nineteenth-century records for their historiographical problems than for providing cultural ballast to a theory of complex play as signalling or encouraging creative potential. Lewis Terman's eugenic studies on intellectual giftedness, conducted longitudinally from I92 I until I986, noted that 48 of his 643 subjects (7 percent) had 'imaginary countries', although he did not record them in any detail. ${ }^{26}$ In 1942, Leta Hollingworth's Children Above I80 IQ similarly reported that three of her six prepubescent subjects played games of imaginary worlds (Center Land, Bornington, and an unnamed colony on Venus), which she interpreted as a general desire to 'organize the play into a complicated pattern [...] in long-sustained, complicated games' that indicated their developmental acceleration. ${ }^{27}$ David Cohen and Stephen A. MacKeith's I99 I study The Development of the Imagination collected case studies through a public survey, interviewing fifty-seven respondents whom they felt conformed to the characteristics of what they termed paracosmic play (derived from paracosm, a neologism for the invented world itself).$^{28}$ Noting the statistical significance of their results, Cohen and MacKeith suggested 'that if we are ever to understand how the imagination develops, we shall have to be able to understand how young children find the skill and motivation to conjure up such remarkable places'. ${ }^{29}$ Most recently, Michele Root-Bernstein's 20I4 study hypothesised that the highly creative population (represented by a survey of MacArthur Fellows) are more likely to develop what she calls worldplay than the 
average population - furthermore, that worldplay might be used as a pedagogical tool to cultivate creativity as part of a national curriculum. ${ }^{30}$ For Root-Bernstein, examples of literary writers like De Quincey, Coleridge, and Jameson exemplify the potential of an exceptional developmental process that transcends cultural context. ${ }^{3 \mathrm{I}}$

Yet there are good reasons to insist on the historical specificity of a genuinely emergent phenomenon taking place among children at the end of the eighteenth century. For one, although Malkin's unusual memoir of his son registers a new scientific interest in accounts of childhood, Thomas's own writings about Allestone also represent a unprecedented type of record produced by children in the course of play itself, 'live' evidence of a new imaginative practice rather than a new trend in representation after the fact. For another, both play's setting and objects, as well as the genres and ideologies which frame it, visibly draw on the available resources of its cultural environs; as Christine Alexander has argued, 'children learn largely by imitation, their early writings [...] mock, cavil, exaggerate, and explore the adult attitudes that surround them and that they encounter in their reading. ${ }^{32}$ William De Quincey, for example, pastiches the travel and scientific literature of his reading into an ignominious attack on Gombroon. Derwent Coleridge likewise recalls Hartley's 'wont to transfer whatever struck his fancy or stimulated his intellect in actual life' $(H C \mathrm{xl})$ into the Ejuxrian world:

Whatever he had seen in London - theatres, tower, laboratory, or chemistry-house, as he called it; whatever struck his fancy in reading, armies, ships, battles by sea and land, news, negociations, alliances, diplomacy - he thought to reproduce in little in his own playground[.] (xlv)

Joetta Harty notes in particular Hartley's reproduction of 'a new Australia', contextualising these children's interests in latitudes and cartography within 'the various shapes and forms of a geography-centred, colonialist, culturally imperialist discourse': James Cook had charted and claimed the coast of New South Wales in I770, concluding the age of aggressive colonial expansion and imagination Joseph Conrad would call 'Geography Militant'. ${ }^{33}$ Such materials provided fresh impetus to childish fascinations with the 'desolate island' and with fantasies of sovereignty, which clearly rehearse older, yet still popular narratives such as Robinson Crusoe. $^{34}$

As I propose, this learning by imitation included a mode of reading and writing Robinson Crusoe which no longer seriously entertained (nor required) Defoe's claim to 'a just History of Fact'. ${ }^{35}$ The acquisition and 
naturalisation of a fictional mode represents a less abstract form of development than of 'giftedness' or creative capacity, and a less visible example of cultural practice in play than the tropes of political news or colonial adventure. The ability to conceptualise fictional worlds lies at the intersection between a kind of inventive cognition and a literary conceit of undiscovered lands. For two of the novelists examined in this book, from a succeeding generation of children born in the early nineteenth century, little of the contents of their imaginary countries survive into their later works - one reason the significance of their play has been underacknowledged or misunderstood in discussions of their literary practices - but a way of doing fiction does. Charlotte Brontës (b. I8I6) and Anthony Trollope's (b. I 8I5) realist novels do not resemble travel narratives, nor feature the 'armies, ships, battles by sea or land' ( $H C$ xlv) to which this generation of children are drawn. What they learn from and demonstrate in play, however, is a conceptualisation of where novel fictions take place: in imaginary worlds adjoined to ours.

\section{Glass Town, Angria, Gondal, and Gaaldine}

The archive known as the Brontë juvenilia is undoubtedly the best preserved and most well-known example of imaginary worlds in this period. Composed roughly between I 829 and I839, an extant collection of poems, narratives, histories, catalogues, maps, and drawings detail the four Brontë siblings' collaborative creation of the nations of Glass Town, Angria, Gondal, and Gaaldine, both resembling and dwarfing the archive of mixed media assembled by Thomas Malkin's father. As the critic Kate Brown points out, Charlotte Brontë's prose contributions to this game 'exceed in length [...] all of Brontë's novels put together', and as Elizabeth Gaskell estimated when she uncovered them in I 856, 'would make more than 50 vols of print'. ${ }^{36}$ Yet since the publication of these voluminous early writings - first in excerpt by Gaskell's Life of Charlotte Brontë in I 857, then more completely by Fannie Ratchford's scholarly edition in I94I - critics have been largely ambivalent about their literary function or significance. In a letter to George Smith, Gaskell raised concerns about the manuscripts she had discovered and deemed 'the wildest $\&$ most incoherent things [...] creative power carried to the verge of insanity'. ${ }^{37}$ Ratchford's work, which exhaustively traces prototypes for the Brontës' canonical plots and characters back to this early writing, locates their value in being 'the laboratory in which developed all the elements that in their several combinations make up The Professor, Jane Eyre, Shirley, and Villette..$^{8}$ 
Alexander, the most recent editor of this material for the 1987 edition, similarly suggests their function as 'both workshop and playground' for novelists-in-development. ${ }^{39}$ Such approaches, tending to debate the juvenilia's significance in the biographical context of the Brontës as a distinct group of novelists, leave open the possibility for a wider interpretation of this material in the context of the paracosmic phenomenon, of fictional or imaginative practices in general, and of the novel as a form.

As I have argued, games of imaginary worlds embody a novelistic logic and history of fiction; in their juvenilia, the Brontës not only work up the materials of their later novels, but they learn the basic protocols of novel discourse. Their procedures of play, which are also procedures of narrative, reflect fundamental assumptions about the relation between fact and fiction. Like the De Quinceys with their latitudes and Coleridge with his new Australia, the Brontës created their new lands in between the literal lines of geographical reference. In the Brontë Parsonage's copy of Rev. J. Goldsmith's A Grammar of General Geography, in the gazetteer of place names at the back of the volume, after the printed entry for 'Eurestenburg; a principality of the Grand Duchy of Baden' and before that of 'Gareta; a celebrated town of Naples', a childish script inserts 'Gaaldine a large island newly discovered in the south pacific'; and again, between Gomera (one of the Canary Islands) and Gondar (a city in modern Ethiopia), 'Gondal a large island in the north pacific'. ${ }^{\circ}$ Again deceptively easy to dismiss as imaginative precocity, such annotations in fact make substantive ontological claims for the narrative, visually insisting that Gondal and Gaaldine are places formally equivalent to actual places, with an equivalent capacity to be specified, documented, and indexed. Moreover, they are explicitly not disguises for an actual place (in which case they would replace or modify an existing entry), nor an elaborate hoax to deceive future users of the gazette, nor the symptoms of a delusional belief. Rather, the Brontës are playing at verisimilitude, supplementing a work of reference as if Gaaldine has been 'newly discovered' in the material world represented by Goldsmith. ${ }^{4 \mathrm{I}}$

The Brontës' additions to the Grammar are strange but true examples of the 'discoveries' intrinsic to the discursive game of the novel, where we pretend to accrue knowledge about unheard-of people and places as if the text is documenting rather than inventing this information. To open Dickens's eighth novel, The Personal History, Adventures, Experience and Observation of David Copperfield the Younger of Blunderstone Rookery (Which He Never Meant to Publish on Any Account), is to pretend in this way that we have 'newly discovered' the life story of an individual encounterable in the world. Nicholas D. Paige has argued that the formal 
boundary between the early novel and its generic predecessors is marked by this 'pseudofactual posture [...] of memoirs, letters, or occasionally eyewitness histories by or about contemporaries of whom no one had heard'. ${ }^{42}$ Readers had to develop a new sophistication about fictions which became increasing indistinguishable from fact on the textual level - as Rose has shown, different populations of readers 'caught on' at uneven historical speeds - learning to perform the cognitive trick that when 'we meet a merely fictional character in a novel [...] we fold them into the world we inhabit without inconsistency'. ${ }^{43}$ This trick is not so much an operation of counterfactual thinking - as some narratologists posit - as of extrafactuality, imagining more than is strictly true about the world. ${ }^{44}$

Due to the social and legal stakes of reputation in the period, literary historians have tended to emphasise the imagined contemporary as an example of the novel's unique interlocking of fiction and fact. 'The key mode of nonreferentiality in the novel was, and still is, that of proper names', Gallagher argues, tracking the rise of novel fiction through its movement from 'a previous language game that assumed a correspondence between a proper name in a believable narrative and an embodied individual in the world' to the modern understanding that 'proper names do not take specific individuals as their referents, and hence none of the specific assertions made about them can be verified or falsified'. ${ }^{45}$ The titles of David Copperfield's favourite eighteenth-century books seem accordingly to hinge their narrative claims upon the existences of 'Roderick Random, Peregrine Pickle, Humphrey Clinker, Tom Jones, the Vicar of Wakefield, Don Quixote, Gil Blas, and Robinson Crusoe $^{\prime 46}$ - a convention which David Copperfield and Jane Eyre themselves follow, and which Watt has argued as the novel's 'significant break with tradition'. ${ }^{47}$ The presence or absence of such persons in the world, and then a developing sense of their pretended reality despite the world, has become 'key' to the critical history of novel fiction.

The Brontë juvenilia remind us, however, that proper names can denote more than persons. What it means to give proper names to specific but non-actual places rather than characters, in fact an older literary practice, has its own, under-examined implications for how the novel came to conceive its particular fictionality. Geography is a different kind of index for truth, as the young Jane Eyre reflects in the process of learning to read:

I considered [Gulliver's Travels] a narrative of facts, and discovered in it a vein of interest deeper than what I found in fairy tales: for as to the elves, having sought them in vain among foxglove leaves and bells [...] I had at length made up my mind to the sad truth, that they were all gone out of 
England to some savage country where the woods were wilder and thicker, and the population more scant; whereas, Lilliput and Brobdignag being, in my creed, solid parts of the earth's surface, I doubted not that I might one day, by taking a long voyage, see with my own eyes the little fields, houses, and trees, the diminutive people[.] (JE 20)

If Jane has not yet learned the rules of fiction, still credulously believing that the realities named by literature have actual correspondences, her strategy for accommodating a growing sense of disbelief is to relocate this referentiality to 'some savage country' where they might still be true. (Brontë's sentence produces a moment where 'the sad truth' to which Jane has made up her mind threatens to be the non-existence of fairies, which is then comically defused by her continued faith in them through a leap of childish logic.) The advantage that the young Brontës - and the reader of Jane Eyre - have over Jane is the ability to make-believe what she actually believes, acting as if Gondal or Thornfield are 'solid parts of the earth's surface' just out of our knowledge, while also explicitly knowing otherwise. If the fictional contemporary always leaves some margin of possibility that they may have actually existed, given the impossibility of a complete knowledge of all historical individuals in early nineteenthcentury England (there is no alphabetised roster into which the Brontës can insert the names of their characters), the rigorousness of geography demands a more explicit acknowledgement of novel fiction's noncorrespondence to actuality. Inventing an imaginary country is a cognitive shortcut to inhabiting this logical space.

Jane's childish progress towards fictional sophistication might suggest an alternative reading of the complex narratological developments in the eighteenth century, the age of 'fictionality in its infancy'. ${ }^{8}$ Naïve readers from the nineteenth century onwards only needed an atlas to realise that places in the novel are not all out there in the world: as a child, Jeremy Bentham too 'admired 'Gulliver's Travels;' [.. .] would have vouched them to be all true', ${ }^{49}$ but as a philosopher, could breezily dismiss the existences of 'countries, such as El Dorado; seas, such as the Strait of Anian; fountains, such as the fountain of Jouvence' ${ }^{50}$ Bentham's wider philosophical project is to eradicate these kinds of speculative or imaginary existences from the systems of truth that govern society and the law, where he believes them to introduce ambiguity and irrationality into just distinctions between facts and lies. But the story of his own maturation recalls a third category of assertion - beliefs and possible truths - which characterises the longer respective histories of these places as speculative actualities. The Fountain of Youth, a trope which originated with Herodotus, 
was already regarded as mythical by the sixteenth century, but until it was replaced by the actual Bering Strait further north, the Strait of Anian featured in published maps as late as 1728. Similarly, expeditions to El Dorado, which famously engrossed Walter Raleigh, continued until I 804. By the time they became Bentham's examples of 'fabulous entities', two of the three had only recently fallen off the map, their possibility to be 'newly discovered' diminishing as the empirical world filled in over time. If Jane must eventually accept the imaginariness of fairies when she fails to find them anywhere (but realise also that the diversion of the tale is still the same), reports of Lilliput graduate into impossibility over the eighteenth and nineteenth centuries, requiring either Derwent Coleridge's interpretation of 'an intentional disguise' ( $H C$ xliv) or a different way of entertaining its reality.

Explicitly fictional worlds become conceptually useful only if the actual world has become ( $\grave{a}$ la Bentham) a complete matter of fact; the creation of Gondal is a deliberately fictional act because it must intrude between the authoritative lines of Goldsmith's gazette. ${ }^{5 \mathrm{I}}$ In other words, the practice of pretence begins where the possibility for speculation ends. As Jason Pearl has argued, naval exploration in the period between 1660 and 1740 rendered 'largely obsolete [...] the once-crucial convention of the sea voyage through unknown waters to unmapped lands', as well as the early modern conceptualisation of 'utopia [...] as a concurrent reality separated from us only laterally'. ${ }^{52}$ Although the elder Malkin recognised an eminent precedent for his son in Thomas More, describing Allestone as 'an imaginary country, somewhat similar to Utopia', Pearl's argument about the decline of utopian fictions marks the difference in historical conditions between the two. ${ }^{53}$ While More and his circle of humanist correspondents kept up a coyness about Utopia's material reality which appears properly pseudofactual, they also had recourse to a persuasive rhetoric of speculative possibility. ${ }^{54}$ More's contributor Peter Giles, in a letter appended to Utopia's first edition, suggests an explanation for why the country 'is not to be found among the cosmographers': that perhaps 'they never discovered the island at all. Nowadays we find all sorts of lands turning up that the old geographers never mentioned'. ${ }^{5}$ This is exactly the kind of explanation which became foreclosed by the end of the eighteenth century and represents a different kind of fictional claim (provisional possibility) to that which I argue distinguishes the novel and Allestone (explicit impossibility).

Gombroon, Ejuxria, Allestone, and Angria mark the point of transition between other worlds as a narrative subject, on the one hand, and as an 
imagined ontology for narrative, on the other. For Pearl, the lateral relation to alterity inherent to the utopian romance, made untenable by new geographical knowledge, diverges into two succeeding tropes: the euchronias (utopias in the future) of Edward Bellamy and William Morris, precursors to the utopias of science fiction, and an internalisation of the genre's conventions into cognition, 'reimagining utopias as a state of mind available anywhere. ${ }^{56}$ Drawing from Defoe's under-examined third instalment, Serious Reflections During the Life and Surprising Adventures of Robinson Crusoe, Pearl notes the solitude of Crusoe's later life in London and its practice of:

[A] kind of interiority that is a remnant of geographic utopias. Imaginary lands engage the imagination and then, disproven, ironically legitimise it [...] the failure of utopian geography establishes interior space as oppositional and counterfactual, a site of recuperative possibility. ${ }^{57}$

The imagined worlds which manifest in play at the end of the eighteenth century, due partly to the popularity of Crusoe, suggest how Pearl's 'utopian remainder' is more widely introjected as a way of enacting fictionality, than of the social and political idealism originally associated with the utopia. By and large, the worlds of play lack ideality in the sense of normative perfectionism or desirability - Gombroon has more problems than most actual countries - but are instead 'ideal' in the sense of 'Existing only in idea, confined to thought or imagination; imaginary: opposed to real or actual.$^{58}$ Rather than for its possibilities as a model for reorganising life, the imaginary land becomes appealing for its narrative conceit and make-believe logic of the 'new discovery', for an available space of invention made plausible.

If the Victorian novel may be the most unlikely place to search for these remnants of utopia, they are nonetheless powerfully present in its rules of reality and imagining - its mode of play. The historical nadir of stories about fantastical lands between the late eighteenth and late nineteenth century, when the novel became almost synonymous with the interiorities of subjectivity and domesticity, is also a period of ascendancy for realist protocols which proliferated imaginary instances and regions of contemporary life. How can a real country have a fictional part (or fictional citizens, or fictional events)? The travel fiction of Robinson Crusoe and Gulliver's Travels propagated the conceit of imagining lands 'out there' over a period when geographical elsewheres were in fact becoming increasingly knowable and disprovable. Closer to home, the imaginary worlds of early nineteenth-century childhoods distilled the logic of utopian 
speculation and transformed it into a more virtual relation between reference and invention - in other words, into novel fiction.

\section{The Castle in the Air}

The goal of this chapter, however, is not to chart (by however unusual a route) the novel's arrival at a familiar endpoint of modern fiction, but rather to defamiliarise our sense of its destination. Drawing connections between a history of play and the development of fiction might account for how things came to be, but it may also move the ground under our feet, revealing utopian foundations beneath the too easily accepted premises of an extra manufacturing town or country house, slipped between lines of reference. A make-believe logic of the fictional world underlies the most basic yet substantive assumptions of novel discourse, from the appropriateness of grieving for Nell to the futility of searching for Thornfield. By inhabiting this logic as a matter of course and taking such assumptions for granted, we often play the novel without knowing it, requiring accounts of its incipient development or initial acquisition to bring their specificity and effects more fully into attention.

For Anthony Trollope, acknowledging what the novel owes to play is a means of articulating a theory of the novel. Trollope has an unorthodox view of the form's function and distinction, which certain of his contemporaries exemplify more than others with novels that afford particular modes of vicarious response he calls, idiosyncratically, 'living with'. As he took measure in a chapter of his Autobiography, 'On English Novelists of the Present Day': Dickens, 'in his best days, always lived with his characters'; Brontë 'lived with those characters' of Jane Eyre and Rochester; Thackeray 'lived with the characters he was creating' ( $A A$ i $52-57$, emphasis added). Yet for all that he advocates an experience of imaginative reality as a critical standard for the novel, Trollope's own practice began with a more ambivalent childhood habit: 'I myself often regarded with dismay when I thought of the hours devoted to it', he confesses, 'but which, I suppose, must have tended to make me what I have been' ( $A A 33)$. By his own reckoning in An Autobiography (published posthumously in I883), from roughly the age of twelve to twenty-eight, ${ }^{59}$ Trollope engaged in a form of private play he describes as 'always going about with some castle in the air firmly built within my mind':

Nor were these efforts in architecture spasmodic, or subject to constant change from day to day. For weeks, for months, if I remember rightly, from year to year, I would carry on the same tale, binding myself down to certain 
laws, to certain proportions, and proprieties, and unities. Nothing impossible was ever introduced, - nor even anything which, from outward circumstances, would seem to be violently improbable. (33)

Consciously or not, Trollope's account takes on the language of play from the I 85 os, echoing Derwent Coleridge's description of Hartley 'day after day, for the space of long years [...] evolving the complicated drama of existence' ( $H C$ xliii), Jameson's admission of having 'carried on for whole years a series of actions, scenes, and adventures', ${ }^{60}$ and as I have suggested, Jane Eyre's internal narration of 'a tale that was never ended' (JE I 32 ). Alongside such accounts, Trollope emphasises the rigorous qualities of play - detail, specificity, and self-consistency over time - which he considers particular to his practice, and which psychologists such as Cohen, MacKeith, and Root-Bernstein would later identify (almost exactly along these lines) as a criteria for the paracosm.

The 'hours invested' in this form of sustained engagement with a specific and continuous fiction, if dismaying to reflect on for the time spent, comes nonetheless to embody Trollope's demand for novelists to remain 'in perpetual intercourse' $(A A$ I 52$)$ with characters. As J. Hillis Miller has also noted, 'The young Anthony Trollope's daydreams were remarkably like the grown-up Trollope's novels' in their shared projection of an ongoing and self-consistent imaginary world, presaging his Chronicles of Barsetshire and its accumulative creation of a fictional county in six novels written over thirteen years. ${ }^{6}$ This connection between imaginative and literary practices is drawn explicitly by Trollope himself, in his contemplation of how play has made him 'what I have been' - a novelist:

I have often doubted whether, had [this play] not been my practice, I should ever have written a novel. I learned in this way to maintain an interest in a fictitious story, to dwell on a work created by my own imagination, and to live in a world altogether outside the world of my own material life. $(A A 33)$

For Trollope, the stakes of play are nothing less than the novel itself, contingent upon the cultivation of a capacity to 'dwell on' fiction. As Cohen and MacKeith suggest, in contrast to games of temporary makebelieve, where 'nothing remains of [children's] efforts and imagination [...] Once the play is over', worldplay is distinctive for representing 'games that didn't disappear and weren't meant to', to which children 'kept returning' over long periods of time. ${ }^{62}$ Root-Bernstein, too, distinguishes her cases for their 'consistent return over some period of time to a specific 
scenario, as evidenced by the naming of place and characters or the elaboration of a continuous narrative'. ${ }^{63}$ This sense of the imaginary world as something that can be returned to, as if it were the same continuous object each time, or something independently 'out there' to be accessed, is for Trollope an indispensable quality of novel fiction; or put otherwise, the inherently virtual effect of formal realism's premise to document what it invents.

This quality therefore consists not just in the remarkable length of the single narrative, typical to records of play, but the assumption or pretence of what Eric Hayot has called the 'persistence' of a virtual world. As Hayot argues, literary works which imply the passing of time between instances of representation, such as 'between individual works set in the same world [like the Barsetshire novels], or even between individual chapters in the same work', suggest 'the 'persistence' of elements of the diegesis beyond the immediate attention of the controlling narrative, ${ }^{64}$ an experience more commonly associated with digital virtuality:

The continued existence of imaginary objects beyond their immediate apprehension by a living audience is known among users of contemporary online virtual worlds as 'persistence'. The term describes the fact that such worlds [...] continue to exist when the individual player stops playing [...] disconnecting narrative and descriptive viability from any single or collective act of perception. Continuity without human presence is thus part of the nature of such games, which could theoretically run on servers long after the extinction of the human race. ${ }^{65}$

The affective experience De Quincey described as a shadow or vapour hardening 'into a rigor of reality' ( $A S 47)$ also constituted, along these lines, a way of considering even the worlds of other children for which he cared much less than his own. Imagining the state of things in Ejuxria after Hartley Coleridge had ceased to play it, De Quincey envisions 'sailing past' to see a realm continuing to run in his absence, where 'the public service must have languished deplorably for want of the royal signature [...] throats there are to be cut, from the product of ten jail deliveries, and nobody dares to cut them, for want of the proper warrant; archbishoprics there are to be filled; and, because they are not filled, the whole nation is running helter skelter into heresy' (45). In what sense does Ejuxria survive the 'extinction' of the mind that made it? Only by the terms of the game in which it was originally played, the same make-believe rules by which novel characters possess a past and future beyond the represented narrative.

Actually, Jane Eyre does not take place anywhere. The worlds of play and the novel do not have servers or far-off islands where they might keep 
ticking over by themselves without human attention (unless one thinks of the material book in this way). Yet part of their imaginative design is the pretence that they do; as if fiction is located on some utopian plane external to subjectivity, or in the language of the digital, stored on an external memory. ${ }^{66}$ As I have shown, this is an experience of form which is also a logical-imaginative structure, without which novels make little sense, much as children playing appear equally nonsensical from outside the agreed-upon fantasy of their game. If, in Paige's objection, certain kinds of cultural theorisation about fiction have been too grandiose in connecting 'the nuts and bolts of literary form' to 'a change in worldview, a cultural mutation, a revolution in what is thinkable by humans, ${ }^{67}$ the formal study of novels is and has been necessarily incomplete without an examination of their preconditions to participation, the fundamental as-ifs to which we must consent (often without thinking) in order even to move the gears of narrative. Moreover, because this as-if-ness is now so naturalised in modern expectations and practices of fiction, the novel's alternative functions and implications as a kind of make-believe - in addition to being a linguistic composition or cultural artefact - have also been underexamined or dismissed as mere escapism.

The accounts of historical play collected here allow us to draw speculative connections between the development of novel fiction and the emergence of a virtual play phenomenon at the turn between the eighteenth and nineteenth centuries, and show how these complementary narratives can help to defamiliarise a modern logic of fictional worlds. Tracing back to how we first learned the rules of a novelistic language game enables us to take fuller stock of their distinctiveness and complexity, their origins and usefulness. In the following author studies, I take up more specific comparisons between specific shared practices between play and the novel: between omnipotence and authorship; improvisation and plot; persistence and narrative closure; sensory imagination and description. Although all the children and novelists in the book employ these practices, each of the following chapters will isolate a single aspect, and pose exemplary cases of play, in order to analyse the greater play-novel analogy in parts - and from that analogy, to propose the critical implications in so foregrounding make-believe as a founding feature of the form. 